\title{
A Educação dos Brasileiros \& o Estrangeiro: breve histórico da internacionalização dos estudos no Brasil ${ }^{1}$
}

\author{
Marina Alves Amorim²
}

\section{Introdução}

As temporadas de estudo no exterior marcam as trajetórias de membros das elites brasileiras ${ }^{3}$, desde o período colonial. Houve um tempo em que era a impossibilidade de cursar a graduação, o mestrado ou o doutorado no Brasil, haja visto a inexistência de universidades ou de programas de pós-graduação no país, somada, obviamente, à distinção garantida pela experiência internacional, que ensejava os deslocamentos. E quando passamos a contar com centros de ensino superior e pesquisa de excelência o fenômeno, que continuou funcionando como marca de distinção social, ganhou novos contornos, não somente no que diz respeito ao aumento considerável do número de viagens de estudo e sua extensão a novos grupos (no caso, aos estratos mais privilegiados das camadas médias), mas também à

\footnotetext{
${ }^{1}$ Vale dizer que o histórico da internacionalização dos estudos no Brasil proposto faz parte da tese Para além de partidas e de chegadas: migração e imaginário entre o Brasil e a França na contemporaneidade. Esse trabalho apresenta os resultados finais de pesquisa para o doutoramento, desenvolvida junto à Université Rennes 2 ou Université d'Haute Bretagne (UHB) e à Universidade Federal de Minas Gerais (UFMG) - Cotutela Internacional de Tese -, com o apoio financeiro do Ministère des Affaires Étrangères e da Coordenação de Aperfeiçoamento de Pessoal do Ensino Superior (CAPES), sob orientação conjunta das professoras Rita Godet e Thaïs Pimentel. Ver: Amorim (2009).

${ }^{2}$ Bacharel em História pela FAFICH/UFMG, mestre em educação pela FaE/UFMG, doutora em letras pela Université Rennes 2 - Université d'Haute Bretagne (UHB) e doutora em história pela FAFICH/UFMG, com estágio pós-doutoral em história concluído na FAFICH/UFMG. Atualmente, encontra-se em estágio pós-doutoral na FaE/UFMG.

${ }^{3}$ Optamos por utilizar o termo elites no plural e não elite no singular, porque fazemos referência não somente aos grupos detentores de grande volume de capital econômico que compõem as camadas mais favorecidas da sociedade brasileira, mas também àqueles detentores de grande volume de capital cultural, sendo que ser altamente capitalizado economicamente não garante, necessariamente, uma alta capitalização cultural e viceversa. Ver: Nogueira (2011). Dentro dessa perspectiva, por exemplo, um jovem que consegue, por mérito intelectual, uma bolsa de pesquisa de uma agência de fomento brasileira ou de uma instituição estrangeira para estudar no exterior pode ser considerado como pertencendo às elites do Brasil, ao menos à elite intelectual, que, segundo Bourdieu (1984), constitui a parte dominada das classes dominantes.
} 
ampliação das modalidades possíveis, o que inclui, por exemplo, os intercâmbios culturais de segundo grau e os estágios linguísticos de curta duração. Procuramos, neste artigo, construir um breve histórico da internacionalização dos estudos no Brasil, além de desvelar as bases de sustentação desse fenômeno ${ }^{4}$.

\section{Ensino Superior \& Estrangeiro}

Não por acaso um dos livros de Cunha (2007) que discute a formação do sistema universitário brasileiro intitula-se A Universidade Temporã, conforme alerta Mendonça (2000). O ensino superior surgiu tardiamente no nosso país; sua real institucionalização ocorreu somente na primeira metade do século passado, entre 1920 e 1940.

O Brasil, ao longo de quase todo o período colonial (1500-1822), constituiu uma exceção na América Latina. Enquanto a Espanha espalhou universidades pelas suas colônias, ao ponto delas contarem com quase trinta no momento das independências, Portugal nos limitou às universidades europeias, em especial, a de Coimbra e a de Évora, únicas então existentes na metrópole. E as inúmeras tentativas frustradas de começar a ministrar cursos de nível superior nos colégios jesuítas denunciam a intencionalidade dessa limitação. Na verdade, ela seria um dos fortes vínculos que sustentava a dependência da colônia, na medida em que garantia a conformação da elite brasileira nos moldes que melhor convinham ao colonizador (Mendonça, 2000).

\footnotetext{
${ }^{4}$ Frisamos que, ao afirmar que a internacionalização dos estudos é um fenômeno típico das elites brasileiras, não estamos negando que ela possa envolver também determinados grupos, como é o caso das famílias brasileiras de origem estrangeira. No entanto, é importante destacar que, ao longo do desenvolvimento de doutorado pleno em Rennes, polo universitário francês de renome internacional que acolhe um número não negligenciável de estudantes brasileiros, sobre a temática em questão, localizamos um número insignificante de brasileiros filhos de pais franceses ou europeus, sendo que aqueles que foram localizados são, claramente, membros das elites brasileiras, ou seja, mesmo que a ascendência estrangeira possa ter sido mobilizada por eles como um trunfo para facilitar a temporada de estudo no exterior, essa viagem para estudar não se concretizaria sem a posse de um conjunto de capitais econômicos e culturais necessários.
} 
Com a vinda da corte portuguesa para o Brasil, em 1808, foram criados alguns cursos de nível superior e até mesmo algumas instituições de ensino superior. No Rio de Janeiro, criou-se, em 1808, a Academia de Marinha e o Curso de Anatomia e Cirurgia; em 1810, a Academia Real Militar; em 1812, o Laboratório de Química; em 1813, a Academia de Medicina e Cirurgia; e, em 1814, o Curso de Agricultura. Na Bahia, criou-se, em 1808, a Cadeira de Economia e o Curso de Cirurgia, Anatomia e Obstetrícia; em 1812, o Curso de Agricultura; e, em 1817, o Curso de Química e o Curso de Desenho Técnico. Além disso, foram criados, em 1809, em Pernambuco, o Curso de Matemática; em 1817, na antiga Vila Rica, atual Ouro Preto, o Curso de Desenho e História; e, em 1821, em Paracatu, cidade do interior de Minas Gerais, o Curso de Retórica e Filosofia. O que justificou o surgimento desses cursos e instituições foi uma demanda premente. Tornado sede do império português, o Brasil precisava contar com certa infraestrutura que garantisse a vida da corte. A defesa militar passou também a ser uma questão importante. E era preciso suprir as lacunas do ensino ministrado nas aulas régias (Mendonça, 2000).

Poucas foram as iniciativas, no que concerne ao ensino superior, durante o Império (1822-1889), tendo os sucessivos governos quase que se restringido à manutenção das obras de Dom João VI. Em 1826, começou a funcionar, no Rio de Janeiro, a Academia Imperial de Belas Artes, fundada por uma missão francesa, da qual fazia parte Jean-Baptiste Debret. Um ano mais tarde, foram inaugurados cursos jurídicos, em São Paulo e em Olinda. O Curso de Engenharia foi separado da Academia Militar, em 1874, dando origem à Escola Politécnica. Por fim, em 1875, ocorreu a instalação da Escola de Minas de Ouro Preto, projeto do engenheiro francês Claude-Henri Gorceix (Cf: Mendonça).

Mesmo assim, a Universidade de Coimbra continuou a ser o centro formador por excelência da fina flor da mocidade, até a segunda metade do século XIX, o que levou Anísio Teixeira a chamá-la de "universidade brasileira". Nossos primeiros 
cientistas, as principais lideranças dos movimentos de independência e quase toda a intelligentsia do período imperial estudaram nessa instituição (Mendonça, 2000). Se é verdade que, a partir do fim da Regência (1831-1840), começou a ocorrer uma diversificação das trajetórias de formação da elite, Portugal não deixou de ser uma passagem obrigatória de imediato, pois é de lá que se costumava rumar para outros centros, principalmente para a França (Brito, 1996).

Foi somente na primeira metade do século passado que o país passou a contar com quatro universidades. Em 1920, foi criada a Universidade do Rio de Janeiro, a partir da agregação de três faculdades isoladas. Em 1927, surgiu a Universidade de Minas Gerais, também constituída da mesma maneira. A Universidade de São Paulo (USP), primeira instituição de ensino superior brasileira a ultrapassar os limites e as ambições da formação profissional, foi fundada em 1934, com forte presença de uma missão francesa, da qual fazia parte Claude Lévi-Strauss. Um ano mais tarde, também com um novo espírito, tivemos o surgimento da Universidade do Distrito Federal, que viria a ser absorvida, em 1937, pela Universidade do Brasil (UnB), essa de cunho mais conservador (Mendonça, 2000).

Brito (1996), na tentativa de estabelecer marcos históricos afinados com o desenrolar das relações entre o ensino superior brasileiro e o internacional, menciona, em princípio, dois períodos. São eles: 1. 1500-1840, quando a formação universitária é feita inteira ou majoritariamente em Portugal; 2. 1840-1930, quando ela passa, gradualmente, a ser realizada no Brasil, sendo que, no que concerne à circulação de estudantes brasileiros no exterior, a metrópole perde, de maneira progressiva, a hegemonia frente a outros centros europeus. Um indício dessa transformação é o local de estudo dos ministros da época. Todos eles tinham estudado em Coimbra, até o final do Primeiro Reinado (1822-1831). No início do Segundo Reinado (1840-1889), eles se dividiam em dois grupos quase equivalentes, aqueles que passaram por Portugal (45\%) e aqueles que provinham de instituições brasileiras (55\%). Já a partir 
de 1853, nenhum deles possuía uma bagagem portuguesa. E, quanto à diversificação das destinações no estrangeiro, entre 1831 e 1889, cinco ministros (8\%) frequentaram universidades em outros países, provavelmente na França.

\section{Pós-Graduação \& Estrangeiro}

No que diz respeito à pós-graduação, Cury (2004) demonstra como o desenvolvimento de programas de mestrado e doutorado no Brasil ocorreu atrelado ao exterior, reconstruindo esse processo desde o início do período republicano, com particular interesse pela segunda metade do século $X X$, quando ele passa a ser resultado de uma verdadeira política governamental de impacto.

A qualificação de professores e de pesquisadores de um país nem sempre pôde ser realizada plenamente com os próprios meios internos. No caso do Brasil, de formação colonial peculiar que não estimulou a formação autóctone de intelectuais e pesquisadores, de seletividade sociopolítica que exclui contingentes enormes, houve impedimentos estruturais para uma afirmação autônoma e ampliada do ensino superior (Cury, 2004, p.112).

O início da pós-graduação no Brasil, na verdade, associa Estado, progresso da ciência e referências internacionais. A começar, por meio da concessão de um número significativo de bolsas de estudo por agências de fomento públicas (em especial, a CAPES, o Conselho Nacional de Pesquisa ou CNPq e a Fundação de Amparo à Pesquisa do Estado de São Paulo ou FAPESP, fundadas, respectivamente, em 1951, 1949 e 1962), professores e pesquisadores foram enviados ao exterior para cursar o mestrado e o doutorado. E, depois do seu retorno ao país, receberam as 
condições necessárias para recriarem, disseminarem e continuarem a desenvolver o que haviam aprendido, com o intuito de fomentar a fundação e a consolidação de programas de pós-graduação. Por outro lado, no momento de se estruturar o sistema, o que ocorreu no início da ditadura militar (1964-1984), adota-se como modelo um paradigma exógeno, o estadunidense - com os seus dois níveis de grau, o mestrado e o doutorado; suas áreas de concentração e de domínio; sua sistemática de cursos e créditos; sua duração variável; seus exames de qualificação; seu domínio em língua estrangeira; seu método de acompanhamento dos estudos e pesquisas por um orientador; sua exigência da dissertação para o mestrado e da tese para o doutorado. Ou seja, diante da necessidade de formar seus próprios cientistas, docentes e técnicos, mais uma vez, é para fora que o Brasil se volta (Cury, 2004).

Atualmente, os programas de pós-graduação das nossas universidades formam e titulam a maior parte dos brasileiros que concluem o mestrado e o doutorado, e as agências de fomento do país investem pesadamente nesses programas. Se houve um tempo em que eram concedidas bolsas de estudo para o desenvolvimento do mestrado no exterior, nota-se que até mesmo os financiamentos para doutorados plenos para além das fronteiras escasseiam, uma vez que contamos com um sólido sistema interno. Tem se apostado, preferencialmente, nos “doutorados sanduíches" e nos pós-doutoramentos, que não só são estadias mais curtas e menos dispendiosas, mas são marcados antes pela perspectiva de troca entre pesquisadores e de inserção do que produzimos no movimento internacional da ciência (Cury, 2004).

Apesar disso, é interessante notar que a política de qualificação no exterior das agências brasileiras de fomento à pesquisa continua bastante agressiva. Entre os anos 1990 e 2000, a CAPES concedeu 2697 bolsas de doutorado pleno. Se considerarmos que o CNPq e as agências estaduais oferecem mais ou menos a mesma quantidade de bolsas, quase nove mil bolsas de doutorado pleno foram concedidas, ao longo do 
período. Os estudantes que receberam financiamentos da CAPES, na última década do século XX, escolheram quarenta e um destinos diferentes, cobrindo todos os cinco continentes. Os três destinos mais escolhidos foram os Estados Unidos (com 2185 bolsas), a França (com 1812 bolsas) e a Grã-Bretanha (com 1091 bolsas) (Cury, 2004).

Teríamos saído de uma época de dependência para com o exterior e entrado em uma de interdependência, segundo Brito (2004). Todavia, é importante destacar que o Brasil se insere nesse movimento internacional de produção da ciência enquanto um país periférico. Dados de 2004 apresentados por Ennafaa (2004-2005) demonstram a assimetria do fluxo internacional de estudantes: $62 \%$ dos estudantes em mobilidade internacional são originários dos países periféricos e se encontram em um país central, $30 \%$ provêm de um país central e escolhem outro país central como destino, somente $8 \%$ provêm de um país central e se deslocam para países periféricos; os Estados Unidos recebem acima de 25\% dos estudantes em mobilidade internacional, mais que a Inglaterra, a Alemanha e a França reunidas, enviando apenas $2 \%$ deles. Ou seja, vivendo no centro do mundo, os estadunidenses não precisam se preocupar em viajar para conhecer o que vem sendo feito em outros lugares, difundir os resultados dos seus trabalhos e intercambiar com os seus pares em uma escala global. Esse não é o nosso caso, e também não é o caso de outros países que ocupam lugar semelhante ao do Brasil na ordem mundial.

\section{Novas Roupagens de um Antigo Fenômeno}

O histórico construído permite compreender como as temporadas de estudo no exterior constituem práticas culturais bastante enraizadas entre nós. Até 1808, aqueles que não estavam destinados ao sacerdócio deviam, obrigatoriamente, deixar o Brasil, para ingressar no ensino superior. Embora a chegada da corte portuguesa (1808) tenha levado ao surgimento de alguns cursos superiores e mesmo de algumas 
instituições de nível superior, cursos e instituições esses que sobreviveram à proclamação da independência (1822) e aos quais vieram se somar, ao longo do Império (1822-1889), algumas novidades em termos de educação superior, a Universidade de Coimbra continuou a funcionar como "universidade brasileira", nas palavras de Anísio Teixeira, até a segunda metade do século XIX. Tal quadro começou a se transformar apenas a partir de meados do século passado, certamente de maneira mais significativa após 1920, com a criação das primeiras universidades no Brasil. Mas isso no que concerne à graduação, pois precisaríamos esperar até a segunda metade do século $\mathrm{XX}$, para assistir à consolidação dos nossos programas de pós-graduação. Sendo que eles foram criados, em grande medida, por pesquisadores que desenvolveram o mestrado e o doutorado no exterior, de acordo com moldes estadunidenses.

Na verdade, como faz questão de frisar Brito (1996), o surgimento de universidades e mesmo de programas de mestrado e doutorado no Brasil não significou o fim da participação estrangeira na formação superior dos brasileiros, mas antes uma complexificação dos itinerários formativos das elites. A possibilidade de cursar a graduação no país, em um primeiro momento, irá somente transferir para outro nível de ensino esse aporte dos países centrais. Mais tarde, com a organização do nosso sistema de pós-graduação, ele seria deslocado de novo da formação para a pesquisa. Além disso, possuir um diploma nacional não impede as temporadas de estudo no exterior. Possuí-lo, ao contrário, vai antes exigir essa complementação, entre a segunda metade do século XIX e a primeira metade do século XX, por exemplo, na medida em que ela garantia um aperfeiçoamento técnico ou científico e, sobretudo, o contato com as correntes de ideias e as elites internacionais.

Dentro desse processo de complexificação das trajetórias escolares de membros das camadas mais privilegiadas da sociedade brasileira que inclui o estudar fora do país, encontram-se, em nossa opinião, também os intercâmbios 
culturais de segundo grau e os intercâmbios universitários para estudantes de graduação, bem como os cursos de língua de curta duração e os programas de estágio ou trabalho no estrangeiro. Isso porque essas modalidades recentes de internacionalização dos estudos, voltadas para uma clientela cada vez mais jovem, parecem desenhar não um novo fenômeno e sim os novos contornos de um processo de reprodução social que nos acompanha desde o período colonial.

Nogueira (1998; 2004; 2008) se dedicou à análise das experiências internacionais de escolarização de filhos de professores universitários e empresários de Belo Horizonte. Para a autora, trata-se de uma nova faceta da nossa realidade educacional, que não pode ser desprezada quando se fala em educação das elites, em função do seu vertiginoso aumento nas últimas décadas entre jovens oriundos de meios sociais favorecidos. Cerca de sessenta mil estudantes viajaram do Brasil para o exterior para estudar, em 2007, sendo que 10\% deles cursavam o segundo grau e participavam de um intercâmbio cultural (Nogueira, 1998).

\section{Desvelando a Internacionalização dos Estudos}

E o que move os pais que investem em "uma dose de Europa ou Estados Unidos para cada filho", nas palavras de um entrevistado de Nogueira (1998, p.118) que deu título ao seu artigo?

A internacionalização dos estudos, não importa em qual nível de escolarização, funciona como uma estratégia educativa de determinados grupos, visando à manutenção das fronteiras estabelecidas entre eles e os grupos detentores de menor capital cultural e econômico, segundo a autora, que retoma as ideias defendidas por Bourdieu (2001). Com a "democratização" do acesso à educação, o sucesso escolar de pessoas pertencentes às camadas sociais mais baixas e o aumento do número de diplomados no mercado de trabalho, ocorre uma desvalorização dos 
títulos, em função da sua banalização. Sendo assim, aqueles que antes se distinguiam dos demais pela sua posse viram a posição que ocupavam ameaçada, e foram levados a reformular rapidamente suas estratégias escolares e a tentar garantir a exclusividade sobre elas, voltando-se para níveis de ensino mais elevados, estabelecimentos mais seletivos ou tipos de escolarização mais raros, como é o caso dos estudos no exterior (Nogueira, 1998; 2008).

Os pais que financiam um intercâmbio cultural não fogem à regra. Eles têm em vista a super preparação dos filhos para obter sucesso no mercado escolar e no mercado de trabalho. Não por acaso, a grande maioria dos estudantes secundaristas que parte para o exterior ruma para um dos países centrais onde se fala o inglês ${ }^{5}$. Por ser a língua mais rentável em uma série de mercados, ele é considerado um saber mínimo obrigatório pelas famílias dos intercambistas. E essas últimas, acreditando na superioridade da aprendizagem de um idioma em um país que o tem como língua oficial, não se contentam em custear cursos livres, o que também fazem e desde muito cedo (Nogueira, 1998; 2008).

De fato, os jovens que partem para viver seis meses ou um ano nos Estados Unidos, na Inglaterra, no Canadá, na Austrália, na Nova Zelândia ou na Irlanda, uma vez de volta ao Brasil, convertem a experiência internacional em vantagens escolares e profissionais: eles obtêm ainda melhores resultados em inglês no colégio; conseguem uma excelente pontuação na prova de língua estrangeira do vestibular, que, diga-se de passagem, é obrigatória nas universidades federais, independentemente do curso superior para o qual se candidata; quando estão na faculdade, têm boa desenvoltura na leitura de livros e artigos publicados em inglês;

\footnotetext{
${ }^{5}$ Para se ter uma ideia em termos quantitativos, dos estudantes de nível pré-universitário que deixaram o Brasil para estudar no exterior em 2001, 35,04\% embarcaram para os Estados Unidos, $19,74 \%$ para a Inglaterra, 18,4\% para o Canadá, 9,06\% para a Austrália, 6, 28\% para a Nova Zelândia e 0,15\% para a Irlanda, o que significa quase $90 \%$ do total. Entre os anos de 1997 e 1998, dos jovens belorizontinos que participaram de programas de intercâmbio cultural, 57,4\% seguiram para os Estados Unidos, 13,2\% para a Inglaterra, 10,3\% para o Canadá, 7,3\% para a Nova Zelândia e 2,9\% para a Austrália, o que equivale a mais de 90\% do total (NOGUEIRA, 1998, p.362-363).
} 
podem postular, mais tarde, postos de trabalho que exigem a fluência em língua inglesa; em uma entrevista para um emprego, contam com o trunfo de dominar bem o idioma, etc. (Nogueira, 1998; 2008).

Para além dessa perspectiva utilitarista, a temporada de estudos fora do Brasil possui outra dimensão mais subjetiva, que é a de garantir aos filhos uma formação cultural e uma abertura de horizontes e de espírito. Ou seja, a própria viagem, o contato com outras culturas e, mais que isso, a vivência em um país central, assumem um caráter formativo. Esses outros objetivos fomentam uma ampliação do capital cultural do jovem, que não somente reflete na escola, embora muitas vezes não de modo imediato ou visível, mas possui uma rentabilidade social e pode se desdobrar também em termos econômicos (Nogueira, 1998; 2008).

O intercâmbio de segundo grau, então, estabelece clivagens entre os que aprenderam uma língua estrangeira, especialmente o inglês, em um país onde a população fala essa língua, e os que aprenderam o mesmo idioma no Brasil; entre os que dominam um savoir faire cultural e os que não o dominam. Poderíamos acrescentar ainda duas outras marcas de distinção social, uma primeira que divide aqueles que possuem trajetórias escolares marcadas pela internacionalização e aqueles que não as possuem, e uma segunda entre aqueles que já moraram em países centrais e aqueles que não tiveram essa experiência, o que, sem dúvida, carrega um significado positivo em um país periférico como o Brasil, onde estudar e morar no estrangeiro ainda é algo muito pouco comum, sendo que se estabelece uma relação toda especial com o centro do mundo (Nogueira, 1998; 2008).

Brito (1991), em sua tese de doutoramento, ao tentar compreender as razões que levam os brasileiros a buscar um diploma de pós-graduação na França, caminha ao encontro do que diz Nogueira $(1998 ; 2008)$.

Segundo a autora, também para esses brasileiros a temporada de estudos fora do país serve como marca de distinção com um valor não negligenciável no mercado 
de trabalho. Se até os anos 1970, a graduação garantia aos brasileiros o acesso a maior parte dos empregos mais valorizados, inclusive o de professor universitário, com a elevação do nível de qualificação da população provocada pela Reforma Universitária de 1968 e pelo surgimento paralelo de um sistema de ensino superior privado, a pós-graduação se impõe, já nos anos 1980, como título necessário para aqueles que querem se diferenciar em meio à massa de graduados que briga por um bom posto ou que trabalha em um determinado estabelecimento. Ou seja, o mestrado e o doutorado, sobretudo quando são obtidos em uma instituição renomada no estrangeiro, pelo menos até muito recentemente, eram capazes de blindar quem os possuía em um processo seletivo e conferir um estatuto privilegiado aos que já tinham conquistado um lugar ao sol (Brito, 1991). Nas palavras de alguns de seus entrevistados:

Eu acho que o doutorado no exterior interfere no emprego que você pode conseguir, tem um efeito mágico, certamente maior do que o doutorado feito no Brasil, por melhor que ele possa ter sido. O rendimento simbólico do diploma estrangeiro é maior que o do diploma nacional (F-1) (Tradução nossa).

O valor simbólico do meu doutorado, se eu o tivesse feito em E., na Inglaterra, com todas as críticas que tenho sobre o sistema inglês de formação, seria maior que o valor do meu doutorado feito no Brasil. O fato de fazer um doutorado no exterior lhe dá uma importância muito maior, mesmo se ele é feito em um centro brasileiro importante, como o CBPF (F-19) (Tradução nossa).

Então, eu comecei a me dar conta de que a universidade no Brasil não era a única via para uma ascensão profissional. É aí que intervém 
um curso no exterior. É um curso universitário com algo mais: é no exterior (F-13) (Tradução nossa).

Quando eu voltei, era uma época de grande agitação política na universidade, logo depois do processo de redemocratização do país. Então, como eu chegava e eu tinha um status adquirido pelo fato dos estudos no exterior, todos os grupos desejosos de tomarem a direção da escola disputavam minha adesão... (F-9) (Tradução nossa).

...quando a gente tem o doutorado no Brasil, na minha área, é como se a gente não tivesse nada. A gente não é considerado um verdadeiro físico, quando a gente tem um doutorado no Brasil. Eu tentei conseguir uma bolsa do $\mathrm{CNPq}$ de jovem pesquisador sem sucesso. Mesmo se os projetos eram interessantes e previam possibilidades de cooperação entre as universidades de M. e de N., o trabalho com grandes computadores do CBPF, nada feito... Eles me responderam, dizendo que eu devia fazer um post-doc no exterior, assim eu teria, talvez, uma chance, depois... (F-19) (Tradução nossa).

Quando eu voltei, tinham pessoas que queriam organizar reuniões, conferências, para que eu expusesse o que eu tinha aprendido e visto aqui. Eu recusei. Você não volta para o seu país para ditar regras (F9) (Tradução nossa) (Brito, 1991, p.129-131).

Em relação aos estudantes brasileiros que não atribuem, em princípio, um valor qualquer ao diploma estrangeiro, considerando que são funcionários públicos e não trabalham nem têm a pretensão de trabalhar na universidade, uma minoria dentre os entrevistados, Brito (1991) faz questão de ressaltar que, nesse caso, o prestígio que a temporada de estudos fora do país lhes garante está ligada antes ao 
fato de morar na França em si que propriamente a um título valorizado no mercado. Escutemos o que diz mais um de seus entrevistados:

O diploma não tem nenhuma importância, é mais uma questão de segurança pessoal, do ponto de vista emocional... Quando nós chegamos lá, tudo é a França, você sabe?! O que a gente veste, tudo, tudo. Outro dia, eu usava um vestidinho brasileiro e todo mundo falou: "Ah, como é bonito! É francês?" (F-2) (Tradução nossa) (Brito, 1991, p.138).

Uma leitura da formação das elites internacionais elaborada por Wagner (2002), tomando como ponto de partida a realidade das escolas internacionais - que Nogueira (2008) com muita perspicácia definiu como uma espécie de internacionalização in loco, já que ela permite o acesso a uma formação bilíngue, um currículo e um diploma internacionais sem exigir o deslocamento geográfico - ajudanos a compreender essa hierarquia entre os estudos realizados no Brasil e os estudos realizados em certos países do mundo ou entre um diploma brasileiro e um determinado diploma estrangeiro, que permeia toda a discussão apresentada até o momento.

Se o sistema educativo é um dos centros, por excelência, de produção e reprodução do nacional, as escolas internacionais, que se ocupam da formação dos filhos dos altos funcionários e dos homens de negócio em exercício no exterior, apontariam, em princípio, na direção da construção do transnacional, na medida em que misturam alunos de diversas nacionalidades, marcados por uma nova cultura ligada à globalização das trocas e aspirantes a um diploma internacional conferido por uma fundação de Genebra, o Baccalauréat International. Todavia, ao realizar uma pesquisa junto às escolas internacionais da região parisiense, Wagner concluiu que, 
para as famílias de expatriados, a superação do nacional caracteriza apenas a esfera do trabalho, sendo que a esfera educacional permanece, de uma forma muito peculiar, a ele submetida (Wagner, 2002).

A vantagem dos alunos das escolas internacionais está antes na acumulação das competências linguísticas e culturais de vários países que na negação das referências e dos saberes de um país, segundo a autora. Dessa maneira, por um lado, a cultura internacional não pode ser definida como uma cultura mundial mais ou menos unificada, que substitui as culturas nacionais. Ela é, ao contrário, o resultado da soma das culturas nacionais. Soma harmoniosa, vale dizer, pois se opta pelas dimensões consensuais das identidades. Por outro lado, o aluno e sua família emergem como representantes do seu país, e, de um enraizamento nas origens da parte deles, depende a riqueza da formação escolar. A educação internacional, então, mantém uma relação com o nacional, que é marcada, ao mesmo tempo, pela distância e pela apropriação. E, para os alunos internacionais, o nacional não constitui um princípio de identificação exclusivo, funcionando como um recurso linguístico, cultural e social, que eles devem aprender a mobilizar internacionalmente (Wagner, 2002).

A cultura internacional está baseada na valorização de culturas nacionais múltiplas; entretanto, diferentes culturas nacionais não têm necessariamente o mesmo valor na cultura internacional. A hierarquia existente entre os países pode ser ilustrada, por exemplo, a partir das posturas adotadas frente ao aprendizado das línguas (Wagner, 2002):

- Todas as escolas internacionais da região parisiense privilegiam o inglês e impõem o francês, alegando sua importância para a integração da criança ou do jovem no meio em que vive. Mas o ensino da língua do país em que está localizada a escola depende da importância dessa língua em um quadro mais amplo. Assim, enquanto os liceus franceses promovem o bilinguismo, na Espanha e na Inglaterra, 
eles oferecem apenas cursos facultativos de grego ou holandês na Grécia e na Holanda (Wagner, 2002).

- O Baccalauréat International reconhece somente três línguas de trabalho, sendo que, em 1991, 86\% dos candidatos optaram pelo inglês, 12,9\% pelo espanhol e 4,3\% pelo francês. Foram as escolas anglófonas e as universidades americanas e inglesas, sobretudo, que o elaboraram, o que faz com que a formação ministrada pelas escolas internacionais se inscreva nas tradições educativas dos Estados Unidos e da Inglaterra, preparando tanto para a prova que lhe confere quanto para o ingresso nas universidades desses países. Dessa maneira, se os estadunidenses, por exemplo, podem permanecer na sua própria língua e, mais que isso, no seu próprio sistema educativo, enquanto acumulam recursos escolares, sociais e simbólicos internacionais, os alunos da maioria absoluta dos países precisam encarar a acumulação de referências culturais múltiplas como via de acesso à cultura internacional (Wagner, 2002).

- Nem todas as nacionalidades dispõem de escolas internacionais, sendo que, quanto maior a importância atribuída à língua de um país, maior a quantidade de escolas internacionais ele terá. Em Paris, as escolas americanas são mais numerosas e importantes. Quase três quartos do total de alunos das escolas internacionais do mundo estão matriculados nas escolas anglófonas, estando elas esparramadas pela maioria das grandes cidades. As escolas estadunidenses têm maior poder de atração, contando, em geral, com menos da metade de alunos estadunidenses (Wagner, 2002).

- Os expatriados que contam com uma língua materna reconhecida, como é o caso dos anglófonos, preocupam-se em transmiti-la aos filhos, independente da ligação que mantêm com o país de origem. No entanto, não é raro que os expatriados que possuem uma língua materna com pouca utilidade fora do seu país, depois de 
alguns anos de residência no estrangeiro, parem progressivamente de utilizá-la com os filhos (Wagner, 2002).

Da mesma maneira que as culturas nacionais não possuem o mesmo valor no âmbito da cultura internacional, a cultura internacional não possui o mesmo valor no âmbito de cada cultura nacional. As famílias levam em conta não somente a hierarquia entre os países, mas também o valor das diversas formações dentro do seu próprio país, fazendo com que as escolhas educativas variem de acordo com a nacionalidade. O Baccalauréat International, nessa perspectiva, impõe-se com mais facilidade onde a passagem por instituições educativas no exterior faz parte das condições de reprodução das elites. Não por acaso, dentre os candidatos ao diploma de Genebra, encontra-se um número importante de jovens dos países periféricos. A Índia, o Irã e a Nigéria ocupam, desde 1970, a décima-primeira, a décima-segunda e a décima-quarta posição, considerando o número de candidatos apresentados. $\mathrm{O}$ número de candidatos originários da América Latina (México, Colômbia e Brasil), mas, sobretudo, de países asiáticos (Coréia do Sul, Filipinas e Taiwan), aumentou bastante, desde 1982 (Wagner, 2002).

Para dar conta da diversidade das relações nacionais com o internacional, convém, portanto, fazer intervir dois fatores. O primeiro diz respeito ao reconhecimento internacional do nacional e opõe nacionalidades dominantes, que podem enfatizar o valor internacional de seus atributos nacionais, aos originários de países dominados do ponto de vista econômico e político que, pelo contrário, devem recalcar os atributos nacionais de sua identidade e assimilarem-se aos modelos dominantes. O segundo fator refere-se ao reconhecimento nacional do internacional e opõe as nacionalidades para as quais os investimentos internacionais vão no 
sentido das exigências do sistema nacional escolar e social, às nacionalidades para as quais essas escolhas educativas são mais arriscadas na competição nacional. A capacidade dos Estados para produzirem sua própria definição da excelência social, capacidade que, em parte, depende do poder político e econômico do país, determina assim definições contrastantes do internacional (Wagner, 2002, p. 181).

No caso específico do Brasil, qual é o lugar internacional do nacional e qual é o lugar do nacional no internacional? DaMatta (2005) responde de forma ainda mais enfática do que Wagner (2002) essas duas perguntas. O autor defende que um contraste decisivo, envolvendo realidades, fantasias e percepções, marca o elaborado universo espacial dos brasileiros. De um lado, há o "aqui dentro" e, de outro, o "lá fora", sendo que "[...] o 'lá fora' é o local onde tudo de bom acontece [...]; ao passo que o 'aqui dentro' é o centro desinteressante de rotinas e práticas primitivas, atrasadas ou, como se dizia no meu tempo de estudante universitário, 'subdesenvolvidas'"' (DaMatta, 2005, p. 57)6. Indo além, DaMatta (2005) chama a atenção para o fato de que esse contraste decisivo se encontra plenamente imbuído de um outro contraste, aquele que opõe países centrais e países periféricos e que foi forjado pelo passado colonial. $\mathrm{O}$ autor caracteriza, então, a imaginação dos brasileiros como sendo de tipo colonizada7.

\footnotetext{
${ }^{6}$ Observem que, assim como propõe Chauí (2000), ao falar da nossa identidade nacional incompleta e lacunar, a primeira dessas categorias ("aqui dentro") opera com a falta, a privação e o desvio, e só faz sentido enquanto uma aproximação imperfeita e inacabada da segunda ("lá fora"), que trabalha, por sua vez, com o pleno ou com o completo.

${ }^{7}$ Talvez, fosse mais apropriado utilizar o termo imaginário e não imaginação. Sobre a distinção entre imaginação e imaginário: "A maior parte dos problemas do mundo das imagens, de fato, foram tratadas, durante longo tempo, ao abrigo da palavra 'imaginação', que designava a faculdade de engendrar e utilizar imagens. Com o declínio de uma certa psicologia filosófica (em meados do século XX), e sob a pressão das ciências humanas, o estudo das produções imagéticas, de suas propriedades e de seus efeitos, a saber o imaginário, suplantou progressivamente a questão clássica da imaginação. Em outras palavras, o mundo das imagens obteve vantagem sobre sua formação psicológica." (Tradução nossa) (Wunenburger, 2003, p.6).
} 
Uma densa, atuante e ainda não estudada imaginação colonizada percebe e impõe uma percepção verticalizada do mundo. Há um suposto "centro" de civilização e superioridade e uma periferia que "desce" desse centro e termina no local onde estamos. O ideal, nessa hierarquia de espaços, seria viver "lá fora" (e, por implicação ideológica, lá em cima) - em Paris, Londres, Nova York e, dependendo da pessoa, Roma ou Berlim -, mas infelizmente somos obrigados a estar nesse Brasil amarga e injustamente percebido como bárbaro, desordenado, pobre e, no limite - haja ingratidão! -, desmerecedor de nossas vidas. (DaMatta, 2005:57)

Falar em imaginação colonizada ou imaginário colonizado significa apontar que a nossa realidade mental, engendrada no contexto da colonização, continua imbuída do mundo colonial e do lugar que o Brasil nele ocupava em relação aos demais países. Ele define, assim, a começar, a nossa forma de pensar o outro e de pensar a nós mesmos. Nas palavras de Chauí:

a "identidade nacional" pressupõe a relação com o diferente. No caso brasileiro, o diferente ou o outro, com relação ao qual a identidade é definida, são os países capitalistas desenvolvidos, tomados como se fossem uma unidade e uma totalidade completamente realizadas. É pela imagem do desenvolvimento completo do outro que a nossa "identidade", definida como subdesenvolvida, surge lacunar e feita de faltas e privações. [...] Assim, a identidade do Brasil, construída na perspectiva do atraso ou do subdesenvolvimento, é dada pelo que 
lhe falta, pela privação daquelas características que o fariam pleno e completo, isto é, desenvolvido. (Chauí, 2000: 27-28)

\section{Considerações Finais}

Ao longo do desenvolvimento de pesquisa de doutoramento, analisamos as trajetórias de oito estudantes brasileiros que estudavam ou tinham estudado na França (AMORIM, 2009). Esse estudo permitiu vislumbrar como o fenômeno da internacionalização dos estudos, abordado, neste texto, na sua perspectiva macrossocial, é vivido na escala individual.

As histórias particulares também revelaram que os brasileiros que viajam para estudar no estrangeiro estão interessados, em geral, em uma formação e em uma experiência valorizadas, no Brasil, nos mercados escolar, profissional e social, o que não quer dizer, necessariamente, de melhor qualidade. Imersos em um processo de banalização dos diplomas, em decorrência de outro processo, esse de "democratização" do acesso à escola, eles acreditam que a estadia lhes garante uma distinção social que pode ser mobilizada na busca por um bom emprego e na conquista de prestígio, garantindo-lhes uma pertença de classe ou lhes permitindo até galgar novos extratos sociais. O que faz sentido, pois, em um país periférico, a reprodução das elites ocorre, tradicionalmente, no estrangeiro.

\section{Referências Bibliográficas}

Amorim, Marina Alves. Para além de partidas e de chegadas: migração e imaginário entre o Brasil e a França na contemporaneidade. 2009. 295f. Tese (Doutoramento em 
História/ Doutoramento em Letras) - Universidade Federal de Minas Gerais/ Université Rennes 2, Belo Horizonte/ Rennes, 2009.

Bourdieu, Pierre. Homo Academicus. Paris: Les Éditions de Minuit, 1984. 304p.

. Os Excluídos do Interior. In: Nogueira, Maria Alice; Catani, Afrânio (Org.) Pierre Bourdieu: escritos de educação. 3ª ed. Petrópolis/RJ: Vozes, 2001. p. 217-227.

Brito, Ângela Xavier de. Construction de l'Espace de Formation Brésilien et Études à l'Étranger: stratégies et "carrière morale" des étudiants brésiliens dans l'université française (1960-1986). 1991. 503f. Tese (Doutoramento em Sociologia) - Université Paris V, Paris, 1991.

. Estudos no Exterior e Construção do Espaço de Formação no Brasil. In: NÓVOA, Antônio et al. (Org.). Por uma História da Educação Colonial. Lisboa: Educa, 1996. p. 167-181.

. Habitus de Herdeiro, Habitus Escolar: os sentidos da internacionalização nas trajetórias dos estudantes brasileiros no exterior. In: Almeida, Ana Maria et al (Org.). Circulação Internacional e Formação Intelectual das Elites Brasileiras. Campinas: Ed. UNICAMP, 2004. p.85-104.

Chauí, Marilena. Brasil: mito fundador e sociedade autoritária. São Paulo: Fundação Perseu Abrano, 2000. 103p.

Cunha, Luiz Antônio. A Universidade Temporã: o ensino superior, da colônia à Era Vargas. São Paulo: UNESP, 2007. 306p.

Cury, Carlos Roberto Jamil. Qualificação Pós-Graduada no Exterior. In: ALMEIDA, Ana Maria et al (Org.). Circulação Internacional e Formação Intelectual das Elites Brasileiras. Campinas: Ed. UNICAMP, 2004. p.107-143.

DaMatta, Roberto. Tocquevilleanas: notícias da América; crônicas e observações sobre os Estados Unidos. Rio de Janeiro: Rocco, 2005. 435p.

Ennafaa, Rhida. Notes de Lecture. Cahiers du Brésil Contemporain, Paris, n.57/58 59/60, p.319-330, 2004-2005.

Mendonça, Ana Waleska. A Universidade no Brasil. Revista Brasileira de Educação, Campinas, n.14, p.131-150, Maio-Ago. 2000. 
Nogueira, Maria Alice. Capital Cultural. In: Zanten, Agnès van (coord.). Dicionário de Educação. Petrópolis/RJ: Vozes, 2011. p. 80-82. Título original: Dictionnaire de l'Éducation.

et al. Fronteiras Desafiadas: a internacionalização das experiências escolares. Revista Educação e Sociologia, Campinas, v.29, n.103, p.355-376, Maio-Ago. 2008.

Viagens de Estudos ao Exterior: as experiências de filhos de empresários. In: Almeida, Ana Maria et al (Org.). Circulação Internacional e Formação Intelectual das Elites Brasileiras. Campinas: Ed. UNICAMP, 2004. p.47-63.

- Uma dose de Europa ou Estados Unidos para cada filho: estratégias familiares de internalicionalização dos estudos. Pro-posições, Campinas, v.9, n.1(25), p.113-131, Mar. 1998.

Wagner, Anne-Catherine. A Mobilidade das Elites e as Escolas Internacionais: as formas específicas de representar o nacional. In: Almeida, Ana Maria; Nogueira, Maria Alice (Org.). A Escolarização das Elites: um panorama internacional de pesquisa. Petrópolis: Vozes, 2002. p.169-181.

Wunenburger, Jean-Jacques. L'Imaginaire. Paris: PUF, 2003. 125p. (Que sais-je?, 649). 